\title{
Dried Plasma
}

\author{
Mouayyad Zaza, Kyle J. Kalkwarf, and John B. Holcomb
}

\section{Abbreviations}

DCR Damage control resuscitation

FDP Freeze-dried plasma

FFP Fresh frozen plasma

FLyP French lyophilize plasma

LP Lyophilized plasma

RBCs Red blood cells

S/D Solvent/detergent

SDP Spray-dried plasma

TBI Traumatic brain injury

TEG Thrombelastography

\section{Introduction}

Hemorrhage remains the leading cause of preventable death in trauma patients [1]. Contrary to the classical teachings of the "golden hour," in patients with severe truncal hemorrhage, peak mortality occurs at $30 \mathrm{~min}$ [2]. For patients who survive long enough to make it to a hospital, the median time to death from hemorrhage is 90-150 min after admission [1,3]. The lethal triad of hypothermia, acidosis, and acute coagulopathy of trauma is well recognized as a common pathway to irreversible shock and death $[4,5]$. Rapid treatment utilizing damage control resuscitation

M. Zaza $(\bowtie) \cdot$ K. J. Kalkwarf · J. B. Holcomb

Department of Surgery, Division of Acute Care Surgery, University of Texas

Health Science Center at Houston, Memorial Hermann Hospital, Houston, TX, USA

e-mail: Kyle.J.Kalkwarf@uth.tmc.edu; John.Holcomb@uth.tmc.edu 
(DCR) with blood components mimicking whole blood in the setting of permissive hypotension, avoiding crystalloid and colloid, followed by prompt surgical hemorrhage control, is the best strategy to prevent traumatic hemorrhagic death and the onset of the lethal triad [1, 4, 6, 7]. Plasma transfusion is an essential part of this approach and remains a significant logistical challenge even today, hence the need for a reliable, shelf-stable, easy-to-carry and administer plasma product such as dried plasma.

\section{Benefits of Early Plasma Transfusion}

The role of plasma in DCR has been reaffirmed time and time again. In 1945, Beecher noted that "Plasma gives more time to get whole blood into the patient" [8]. Multiple US large center retrospective cohorts showed that 24-28\% of severely injured trauma patients are found to be coagulopathic on admission. Coagulopathic patients have significantly higher mortality rates, while the degree of coagulopathy correlated with the severity of injury [9-11]. Analysis of the German Trauma Registry yielded similar results with rates of coagulopathy up to $34 \%$ as well as a direct correlation between the amount of crystalloid received prehospital and an increasing degree of coagulopathy [12]. Looking back at the first decade of war in Iraq, $33 \%$ of combat casualties were coagulopathic on admission, which correlated with a fivefold increase in mortality [13]. These data highlight the importance of recognizing the early onset of the coagulopathy of trauma at the time of injury, as well as endothelial damage, which plasma has been shown to correct [14]. Therefore, correction of coagulopathy should not be delayed until laboratory values are available to guide therapy and goals of care. The approach to the trauma patient should aim at preventing and correcting this coagulopathy as soon as possible to decrease its effects on mortality and progression of shock.

The importance of balanced resuscitation to include a high ratio of plasma delivered early became evident in the Iraq War where a survival advantage was noted in patients receiving close to $1: 1$ plasma-to- $\mathrm{RBC}$ ratio during massive transfusion compared to those who received less plasma [15]. During this conflict, over 335,000 units of blood products were transfused with nearly 110,000 being plasma $[16,17]$. Analysis of combat casualties over 10 years revealed improved survival in those receiving a higher ratio of plasma and platelets to blood [13]. By 2010, clinical practice guidelines implemented by the Department of Defense (DoD) led to almost $100 \%$ of combat massive transfusions to be at a $1: 1: 1$ ratio [18]. The PROMMTT trial then showed that early plasma administration was associated with reduced mortality in the first $6 \mathrm{~h} \mathrm{[3].} \mathrm{Following} \mathrm{that,} \mathrm{the} \mathrm{PROPPR} \mathrm{trial} \mathrm{demonstrated}$ that patients transfused with a higher plasma ratio achieved more hemostasis and had less early death due to exsanguination [19].

A retrospective review of patients receiving thawed plasma available in the ED showed shorter time to plasma transfusion (43 vs. $89 \mathrm{~min}$ ), a reduction in blood transfused over $24 \mathrm{~h}$, and decreased 30-day mortality [20]. A recent review of US combat casualties in Afghanistan rescued by medical evacuation (MEDEVAC) units 
showed that early blood product transfusion prehospital or within minutes of injury resulted in greater 24-h and 30-day survival [21]. In a large civilian cohort from a level 1 trauma center, prehospital administration of blood products including RBCs and plasma has been shown to be feasible and beneficial with improved acid-base status on admission and decreased overall blood product use in $24 \mathrm{~h}$ as well as a reduction in the risk of death in the sickest patients over the first $6 \mathrm{~h} \mathrm{[22].} \mathrm{All} \mathrm{these}$ findings point toward the need for a method to deliver early plasma in a reliable fashion.

Plasma produces superior volume expansion when compared to crystalloids, allowing less volumes infused to match volume lost, faster hemodynamic recovery, and decreased third-spaced volume [23]. It is important to use plasma as the primary resuscitation fluid for patients who are bleeding [4]. Other benefits of plasma stem from its ability to mitigate the effects of shock on physiology. The role of plasma in the correction of the endotheliopathy of trauma has been reported in multiple studies and is likely more important than correcting coagulopathy. The mechanism of action is thought to be through promoting systemic vascular stability and preventing endothelial permeability, coagulopathy, and inflammation which eventually lead to shock and end-organ failure [24, 25]. Moreover, in a rat model of injury and shock, plasma was able to restore the endothelial glycocalyx, improve syndecan-1 expression, and correct lung injury caused by shock [26].

In a swine model of traumatic brain injury (TBI) and hemorrhagic shock, transfusion of fresh frozen plasma (FFP) decreased neurologic impairment and hastened recovery to baseline cognitive function when compared to saline infusion [27]. Neuroprotective effects of plasma in hemorrhagic shock and TBI are thought to be due to improved cerebral perfusion, decreased glutamate-mediated excitotoxicity, and reduction in mitochondrial dysfunction as demonstrated in animal models [28]. Plasma also reduced the size of brain lesions and swelling in multiple swine models of TBI and hemorrhagic shock [29, 30]. It also incurs neuroprotection by providing higher brain oxygenation and cerebral perfusion profiles [30]. In humans, a large retrospective cohort analysis showed that in the subgroup of patients with multifocal intracranial hemorrhage, early administration of plasma was associated with a survival benefit [31].

\section{Logistical Challenges in Plasma Transfusion}

Unfortunately, delivery of early balanced resuscitation is fraught with strategic and logistical challenges. In the USA, half of all trauma patients are cared for outside of levels 1 and 2 trauma centers, where blood products are frequently not readily available [32]. In the military, forward surgical teams (FST) were developed to provide immediate support and treatment to injured soldiers. They used to only carry red blood cells (RBCs) for transfusion, and more recently, they are able to provide plasma but not platelets [33]. Warm fresh whole blood (WFWB) is available in these circumstances and has been shown to improve survival in combat casualties treated by FST [33]. These challenges, along with misconceptions regarding the 
role of blood products in resuscitation, led to the overuse of crystalloids and its own set of unique complications. Excessive crystalloid resuscitation has been shown to be detrimental, while balanced blood product resuscitation decreases the onset of acute respiratory distress syndrome (ARDS) and abdominal compartment syndrome and improves survival $[32,34]$.

The recognition of the importance of early, balanced DCR has led many trauma systems in the USA, and around the world, to search for novel approaches to provide blood products as soon as possible to severely injured trauma patients. These include carrying them in the prehospital setting and having them readily available in the ED. The logistical difficulties in providing FFP transfusions early in trauma are based on the need for reliable cold storage facilities, specialized transport equipment and personnel to provide them, and a lengthy thawing process. There is also a significant loss of up to 50\% due to bag breakage during transport and thawing [35].

FFP is prepared through separation from whole blood and stored at $-18{ }^{\circ} \mathrm{C}$ or colder with a shelf life of about 1 year. The thawing process requires a $30-37{ }^{\circ} \mathrm{C}$ agitated water bath or a warming device cleared by the US Food and Drug Administration; this takes 15-30 min [36]. Thawed FFP should be immediately used but can be stored between 1 and $6{ }^{\circ} \mathrm{C}$ for up to 5 days. All those factors preclude its immediate availability and delay administration in many settings such as austere environments, the battlefield, and smaller hospitals with limited blood banking capabilities. Of great importance and increasing realization is that these same limitations apply in the larger centers as well.

\section{History of Lyophilized Plasma}

The use of plasma in the resuscitation of trauma and hemorrhagic shock began with the work of Dr. John Elliot, who in 1936 devised a mechanism to separate plasma from red blood cells and store it in a vacuum bottle. He believed plasma was all that was needed to treat hemorrhagic shock [37-39]. Elliot utilized pooling by mixing the plasma of up to eight donors together to neutralize anti-A and anti-B antibodies and eliminate the need for cross-matching [38, 40]. Reports of treating shock with dried plasma go back as early as 1938 [41]. In 1940, the British Army called upon the American Red Cross to provide plasma shipped directly to London, and the blood plasma for Great Britain project started [42, 43]. The "Blood for Britain" campaign resulted in almost 15,000 units of blood donated from 1940 to 1941 in New York City alone with the majority used to produce liquid plasma, while the RBCs and platelets were discarded. The program was then stopped due to high incidence of bacterial contamination in liquid plasma [42, 43].

Meanwhile, Dr. Max Strumia was experimenting with turning Elliot's liquid plasma into a sterile powder and refined the drying process by inventing a device for freeze-drying under a vacuum $[37,44]$. This was followed by production of several hundred units of dried plasma for testing by the US Army and Navy. In 1941, freezedried, or lyophilized, plasma was approved for use by the Council on Pharmacy and Chemistry of the American Medical Association. Boxes were designed containing 
the dried plasma in a bottle accompanied by a bottle of sterile water for reconstitution [37]. Lyophilized plasma use started in WWII where millions of units were produced by the American Red Cross and administered by the US and British armies and also distributed to the Allied Forces [17, 37, 42]. It was the primary mode of resuscitating combat casualties for most of WWII.

The recognition of serum hepatitis as a result of pooled lyophilized plasma transfusion caused it to fall out of favor. It continued to be used in the Korean War but was abandoned altogether in the 1950s [37, 42]. The French military continued to produce lyophilized plasma through the mid-1980s when HIV transmission via blood transfusion was recognized. They resumed production in 1994 utilizing small donor pools (under 11 donors) and amotosalen with UV light processing for pathogen reduction [54]. During the same time, the German Red Cross started processing pooled plasma with a solvent/detergent (S/D) treatment as a method of pathogen inactivation. This continued through the early 2000s when the recognition of possible prion disease transmission caused them to switch to a single-donor approach $[42,45]$.

\section{Efficacy and Safety of Dried Plasma}

\section{Production and Forms of Dried Plasma}

Production of dried plasma is achieved in two ways: freeze-drying, also known as lyophilization, or spray-drying. Lyophilization is achieved by freezing the plasma under a vacuum in a glass container for several days, which decreases the water content to 1-2\% [45]. Spray-dried plasma production utilizes atomization of liquid plasma via pressurized drying gas to droplets which are then exposed to hot gas (up to $150{ }^{\circ} \mathrm{C}$ ) in a drying chamber followed by rapid evaporative cooling. This method can dry a unit of plasma $(\sim 250 \mathrm{~mL})$ in approximately $25 \mathrm{~min}[17,46]$. Dried plasma can then be reconstituted to its original volume or a concentrated form. Multiple pathogen inactivation methods are available to use during the process, and the choice depends on the manufacturer's preference and experience.

\section{Pathogen Inactivation}

Newer and more accurate viral detection and pathogen inactivation methods have led to the improved safety of blood products, reducing the residual risk of transfusiontransmitted HIV-1 and HCV to approximately 1 in 2 million blood units [47]. Pathogen inactivation methods used for plasma include solvent/detergent (S/D) treatment and photochemical inactivation techniques [17]. S/D treatment, which is FDA-approved, binds lipid-enveloped viruses and bacteria to inactivate them followed by a filtration process to remove cells and debris, but it has no effect against non-enveloped viruses and prions [48]. Rigorous screening standards require testing donors for non-enveloped viruses twice at a 6-month interval to decrease the risk of 
transmission. Moreover, photochemical inactivation utilizes a photosensitizer that binds the DNA and RNA of pathogens, including non-enveloped viruses, and nucleated cells, followed by ultraviolet light exposure to inactivate them [49]. INTERCEPT (Cerus Corp., Concord, CA) is an FDA-approved system, which uses amotosalen (a psoralen molecule) to bind DNA and RNA followed by UV light activation [50]. The Mirasol System (Terumo BCT, Lakewood, CO), which uses riboflavin as the photosensitizer, is currently approved for clinical use in Europe but only approved for investigational use in the USA and Canada [51]. Methylene blue can also be used with visible light exposure [52].

Standard S/D treatment causes a decrease in vWF activity (24\%), factor V (37\%), protein S (44\%), and alpha-2 antiplasmin (79\%). Similarly, amotosalen + UV light reduces factor VII $(23 \%)$ and factor VIII $(27 \%)$ [17, 48]. A newer S/D treatment product, Octaplas LG (Octapharma, Lachen, Switzerland), received FDA clearance in 2013 and employs a prion reduction step and a modified S/D process that better preserves factor levels [17].

\section{Buffering and Reconstitution}

Reconstituted porcine lyophilized plasma is alkalotic with a $\mathrm{pH}>8.5$, making it highly lethal when injected in swine due to their lack of ability to buffer their plasma [53]. Human lyophilized plasma is also alkalotic with a $\mathrm{pH}$ near 8; however, it is well tolerated clinically in humans [54]. This increase in $\mathrm{pH}$ after lyophilization is attributed to the loss of bicarbonate during the drying process. Multiple acidic buffering solutions were studied to evaluate their effect on the hemostatic properties of lyophilized plasma. For example, when ascorbic acid (vitamin C) is added to lyophilized plasma (LP), 84\% of the coagulation factor activity was maintained [55].

In a swine model of polytrauma and hemorrhagic shock, a significant decrease in interleukin-6 (IL-6) levels was observed in all LP-treated animals compared to those receiving FFP, suggesting an anti-inflammatory effect [55]. This was corroborated by another study using concentrated LP (50\%) that showed buffering with ascorbic acid resulted in reduced serum levels of IL-6 and TNF [56]. Another study examined the effect of other buffers, such as citric acid and hydrochloric acid, on lyophilized plasma. No difference in physiology, coagulation parameters, or blood loss was noted, but animals receiving ascorbic acid had lower IL-6 levels and less oxidative DNA damage [57]. Using higher concentrations of ascorbic acid didn't affect the physiologic benefits of LP, but no improvement in the anti-inflammatory effects or further decrease in DNA oxidative damage was detected [53].

The type of fluid used to reconstitute dried plasma has not been shown to affect the degree of inflammation or oxidative DNA damage induced by shock in a swine model of polytrauma and hemorrhagic shock [58]. However, the type of fluid used for reconstitution does affect the hemostatic efficacy and ability of lyophilized plasma (LP) to mitigate the effects of shock. Animals treated with LP reconstituted with sterile water and lactated Ringer's (LR) had less blood loss compared to those reconstituted in normal saline (NS) and Hextend. The group that received Hextend had persistently elevated INR values and contained the only animal that did not 
survive the experiment. Serum IL-6 levels were lowest in the sterile water group when compared to NS [59]. The optimal solution for buffering lyophilized plasma in humans is unknown and will require further investigation. For now, sterile water is used to reconstitute human LP.

\section{Lyophilized Versus Fresh Frozen Plasma}

The process of freezing and thawing plasma is not benign and has several detrimental effects on coagulation proteins. Never-frozen liquid plasma was found to have a superior coagulation profile and factor activity, as well as thrombin generation potential, when compared to plasma from thawed FFP [60]. Thawed plasma was compared at day 0 and after storage at day 5, and a significant degradation of clotting factors was detected in the older product, with a $40 \%$ reduction in thrombin generation potential and significantly decreased hemostatic profile on thrombelastography (TEG) analysis [61]. Thawed FFP decreased vascular permeability in vitro by a factor of 10; however, that effect decreased to only a factor of 2.5 when 5-dayold thawed plasma was used [62]. These findings reinforce some of the advantages of dried plasma over FFP.

\section{Concentrated Dried Plasma}

Concentrated, low-volume reconstitution of lyophilized plasma $(50 \%)$ has been demonstrated to be safe in a swine polytrauma model of hemorrhagic shock with similar physiologic effects, hemostatic properties, and coagulation parameters (INR and TEG) [63]. This could have logistical advantages in packaging and transport on the battlefield as well as in austere environments. The effects of infusing this hypertonic, hyper-oncotic fluid are unknown in humans and will require careful evaluation.

Spray-dried plasma (SDP) at original concentration was compared with triple concentrated SDP in the resuscitation of a swine model of polytrauma and hemorrhagic shock. In vitro evaluation of coagulation parameters of SDP compared with FFP did not reveal any difference between the two products. However, tripleconcentration SDP showed an increase in clotting factor activity and prolonged PT/ PTT. Treatment with all three formulations corrected INR rapidly and increased clot strength (TEG-maximum amplitude (MA)). This confirmed that concentrated, lowvolume SDP is as effective as FFP and regular SDP in reversing trauma-associated coagulopathy [64].

\section{Coagulation Profile of Dried Plasma}

The accepted standard for factor loss in frozen then thawed plasma is 25-40\% [65]. In vitro analysis of swine FFP vs. lyophilized plasma (LP) coagulation tests (PT, PTT, INR, fibrinogen) did not reveal any statistically significant difference. 
Reconstituted LP has been shown to maintain an average of $86 \%$ of coagulation factor activity when compared to FFP [66]. In comparison, spray-drying causes reduction in several factors including $25 \%$ for fibrinogen and protein $\mathrm{S}, 50 \%$ for vWF activity, and $70 \%$ for factors V and VIII. However, this has been shown to have no effect on the ability of SDP to generate thrombin [67]. On the contrary, after a year of storage at $-25^{\circ} \mathrm{C}$, lyophilized plasma had no significant change in clotting factors activity when compared to fresh plasma [68]. Lyophilized plasma stored as long as 30 years had similar preservation of components [69].

\section{Studies in Animal Models of Shock}

Multiple studies demonstrate the safety and efficacy of lyophilized plasma (LP). In a series of studies using a swine model of polytrauma and hemorrhagic shock, LP demonstrated superior hemostatic efficacy to FFP when combined with RBCs in 1:1 ratio. Concentrated LP reconstituted to $50 \%$ of its volume was also well tolerated and equally effective in correcting shock physiology when compared to unconcentrated LP [56]. In another study, fresh whole blood (FWB), FFP, and LP all corrected coagulopathy equally in a swine model. There was $85 \%$ mortality in the crystalloid only group and no mortality in any of the blood products groups [66]. Another study showed that when compared with colloid alone, 7-day survival was superior in animals that received spray-dried plasma - this effect was equivalent to that seen in animals that received whole blood [70]. Moreover, animals receiving balanced LP-to-RBC had significantly less blood loss than those receiving FFP or LP alone, and LP was as effective as FFP in reversing coagulopathy in this animal model [55].

Lyophilized plasma (LP) demonstrated similar effects as FFP, both in vitro and in vivo, on reducing endothelial cell permeability, increasing trans-endothelial resistance, decreasing leukocyte-endothelial binding, and preserving adherens junctions. In an in vitro mouse model of hemorrhagic shock, LP and FFP both equally reduced pulmonary injury, inflammation, and vascular permeability [71]. Spray-dried plasma (SDP) also reduced vascular permeability and other indicators of endothelial damage as well as FFP [72]. FFP and SDP equally decreased shock-induced pulmonary vascular permeability in vivo. SDP was also equivalent to FFP in the correction of shock in a mouse model. They both reduced alveolar wall thickening, leukocyte infiltration, and the breakdown of EC junctions [73].

\section{Neuroprotective Effects of Lyophilized Plasma}

Plasma has been shown to have multiple neuroprotective effects in traumatic brain injury. In a swine model of polytrauma, hemorrhagic shock, and TBI, both lyophilized plasma (LP) and FFP were shown to decrease brain lesion size by $50 \%$ after $6 \mathrm{~h}$ of injury when compared to saline infusion; swelling was also 54\% less in plasma-treated groups [74]. A follow-up study to evaluate the long-term effects of 
resuscitation with FFP vs. LP on neurological outcomes showed similar recovery of cognitive function in studied animals. The brain lesion size was significantly smaller in LP group on experiment day 3, but this effect dissipated by day 10 [75]. Another large 30-day animal study recently showed similar neuroprotective results with faster return to baseline neurological function in animals treated with LP and FFP vs. NS [76].

\section{Modern-Day Lyophilized Plasma}

Since its reintroduction in the 1990s, lyophilized plasma has been used in a variety of settings around the globe. Currently, the largest two manufacturers of lyophilized plasma are the French Military and the German Red Cross. Multiple accounts of the use of lyophilized plasma have been reported, including administration at the point of injury, in the ED and in the ICU. French lyophilized plasma (FLyP) is used by US military special operations under an agreement between the French and US governments as an expanded access investigational new drug application [15, 17, 77]. German lyophilized plasma, known as LyoPlas N-w, has been carried by UK foot patrols since 2012. The use of LyoPlas N-w was easily integrated into the first responder care package. One case of successful usage by the British Military is reported in the literature [78]. The National Bioproducts Institute in South Africa also produces a pooled, S/D-treated, ABO-universal lyophilized plasma, Bioplasma FDP, which has been in use in South Africa since 1996, with a strong record of safety [79].

The Norwegian helicopter emergency medical service experience with the use of lyophilized plasma (LyoPlas N-w, AB) during a 12-month period reported transfusion of 16 patients having sustained blunt and penetrating trauma, as well as nontraumatic hemorrhage (ruptured AAA, upper GI bleeding, etc.). Two patients died on scene, and the remaining were alive at 30 days. No transfusion-related complications were reported. Lyophilized plasma is stored at room temperature in the fastresponse car and in the helicopter, making it readily available. Pre-transfusion hypotension was seen in $62 \%$ of the patients, but only $12 \%$ were still hypotensive at the time of admission. Median systolic blood pressure increased after prehospital lyophilized plasma transfusion in all patient categories. $68 \%$ of the patients received emergency surgery after arrival at the hospital [80].

The Swedish Armed Forces also use lyophilized plasma, and the first civilian helicopter emergency medical systems in Sweden started carrying the product in 2015. They published a case report describing a patient with carotid artery injury due to a high-velocity gunshot wound to the neck and in-flight reconstitution and administration of lyophilized plasma (LyoPlas $\mathrm{N}-\mathrm{w}$ ) in a Medevac helicopter. The reconstitution of LyoPlas $\mathrm{N}-\mathrm{w}$ powder took about 4 min in a dark Black Hawk helicopter cabin. The hemodynamic stability of the patient improved after administration [81].

The Israeli Defense Force Medical Corps (IDF-MC) introduced lyophilized plasma, in the form of LyoPlas N-w, to its protocol of prehospital trauma care and 
transfusion in 2013 [82]. A case report of its use in a civilian after a motor vehicle accident described their first experience with point-of-injury administration of lyophilized plasma [83]. This was followed by a retrospective review of 109 patients who were transfused with lyophilized plasma from 2013 to 2016. The majority $(83 \%)$ of patients received only one unit of LyoPlas N-w, and only $8.2 \%$ received prehospital blood transfusions. There were five instances $(4.6 \%)$ of difficulty with administration after reconstitution mainly due to low flow rates. Side effects were reported in only one female patient who developed chills and shivering during infusion which stopped upon prompt discontinuation [84]. This study is a real-life example of utilizing prehospital lyophilized plasma in early resuscitation of trauma casualties demonstrating safety and feasibility.

\section{French Lyophilized Plasma (FLyP)}

Dr. Jean Julliard started producing freeze-dried plasma in 1945 after its inception by the US military in WWII. By 1950, the Centre de Transfusion Sanguine des Armées (CTSA) became the first European center to produce lyophilized plasma. During the Indochina War, almost 40,000 units of lyophilized plasma were delivered to the French military. Production was suspended in 1985 due to concerns for HIV transmission. In 1991, production restarted with the first Gulf War and has continued since that time [54].

Since 1994, French lyophilized plasma (FLyP) is made using a pool of less than 11 donors. Pooling based on blood type selection allows the dilution and neutralization of natural anti-A and anti-B hemagglutinins, making FLyP a universal donor product compatible with any recipient blood type. Since 2003, it is also being leukoreduced. Starting in 2010, plasma from women with a history of pregnancy is tested for HLA antibodies and excluded if positive. That was the same time that FLyP started undergoing amotosalen and UV light processing as a pathogen DNA/ RNA inactivation method. This process was chosen over solvent/detergent treatment due to better preservation of clotting factors. The French hemovigilance program has been monitoring FLyP since 1994, and so far, no reactions or infectious complications have been reported out of more than 1100 units transfused [54].

FLyP is packaged in glass bottles, shelf-stable in ambient temperatures between 2 and $25{ }^{\circ} \mathrm{C}$ for 2 years, and easily rehydrated with $200 \mathrm{~mL}$ of water in less than 3 min, allowing for immediate transfusion with RBCs. FLyP contains all clotting factors and proteins. After more than 2 years of storage at ambient temperature, the fibrinogen and clotting factor levels of FLyP are equivalent to FFP [85]. Despite a certain level of factor reduction (20-25\%), lyophilization has not been shown to alter in vitro hemostatic efficacy of plasma. When reconstituted, FLyP has a $\mathrm{pH}$ close to 8 [54].

In 2011, FLyP was authorized by the French Agency for the Sanitary Safety of Health Products (AFSSAPS) for use in civilians in austere settings or until thawed plasma became available [54]. Clinical efficacy of FLyP was studied in a prospective trial on $87 \mathrm{ICU}$ patients in Afghanistan and was found to be safe and efficacious 
in the management of polytrauma and shock [86]. Furthermore, the difference in administration times between FLyP and FFP in a level 1 trauma center was studied. Retrospective analysis showed significantly less time to product administration between patients receiving FLyP vs. FFP (median 15 vs. 95 min). This is consistent with similar reports in the literature of time to FFP transfusion [21]. Subsequently, time to achieve 1:1 resuscitation ratio with RBCs was shorter in FLyP group. There were also significantly less cases of massive transfusion utilization and RBC transfusion in the FLyP group compared to the FFP group (7 vs. 45\%). No differences in hospital length of stay, ICU length of stay, or 24-h mortality between the two groups were noted [87].

Recently, a randomized open-label clinical trial of 48 patients who were assigned to receive 4 units of FLyP or FFP within $6 \mathrm{~h}$ of injury was completed. Patients in the FLyP group demonstrated less time from randomization to infusion compared to those in the FFP group (median 14 min vs. $77 \mathrm{~min}$ ). This led to higher levels of fibrinogen achieved within 45 min of randomization, as well as a greater improvement in INR, factor V, and factor II levels. The difference in coagulation parameters between the two groups remained significant at $6 \mathrm{~h}$. However, there was no difference detected in mortality between the two groups [88].

\section{German Lyophilized Plasma (LyoPlas N-w)}

In the 1990s, the German Red Cross Blood Service West produced solvent/detergent (S/D) treated lyophilized plasma using pooled plasma. Due to concern for Creutzfeldt-Jakob-type prion disease transmission, which is not inactivated by standard S/D treatment, pooled plasma was replaced with single-donor lyophilized plasma in 2007 [45]. This product is licensed under the name LyoPlas N-w (German Red Cross Blood Service West, Hagen, Germany).

Quarantined plasma from a single donor is stored frozen for at least 4 months until the donor returns for retesting for HIV, hepatitis $\mathrm{C}$ virus, hepatitis B virus, hepatitis A virus, and parvovirus B19. After the quarantine, the plasma is thawed and connected by sterile docking to the patented steam-sterilized "bottle-in-bag" system, which consists of a glass bottle and a rubber stopper inside a plastic bag. During transfer into the glass bottle, the plasma passes through a filter with a nominal pore size of $0.2 \mu \mathrm{m}$. Once $200 \mathrm{~mL}$ of plasma is transferred, the bottle is closed with the stopper and removed from the system. Plasma is then frozen to $-30{ }^{\circ} \mathrm{C}$ followed by lyophilization in specially designed freeze-dryers. The lyophilization is accomplished by a stepwise increase of the temperature from $-45^{\circ} \mathrm{C}$ to $+15^{\circ} \mathrm{C}$, resulting in water content below $1 \%$ [45].

Sterile water for reconstitution $(200 \mathrm{~mL})$ is included in the LyoPlas N-w kit and accomplished within 10 min depending on the plasma composition and water temperature. Transfusion can be accomplished via the glass bottle or the plastic bag, which allows for pressure infusion if needed. After storage at $2-8{ }^{\circ} \mathrm{C}$ for 24 months, LyoPlas N-w only had a $10 \%$ reduction in factor V, VIII, and vWF. All other factors remained stable. Storage at room temperature, however, led to $54 \%$ decrease in 
fibrinogen levels and vWF activity. This is why the shelf life of LyoPlas N-w has been restricted to 15 months only. After reconstitutions, factor degradation increases over time at room temperature. At $48 \mathrm{~h}$, factor VIII and protein S levels decreased by 66 and 50\%, respectively. Only $10 \%$ degradation of those factors was noted in the first $6 \mathrm{~h}$, however. This is why it is recommended to use LyoPlas N-w within $6 \mathrm{~h}$ of reconstitution [45].

From 2007 to 2011, a total of 237,850 units of LyoPlas N-w were provided to hospitals, doctors, and the German military compared to 343,821 units of FFP delivered during the same time period. This reflects the wide use of LyoPlas N-w in Germany (41\% of all plasma used) under various clinical settings requiring transfusion and not just trauma resuscitation. The rates and types of transfusion-related complications reported between 2007 and 2011 were similar for FFP and LyoPlas N-w (0.018 vs. $0.023 \%$ ). No viral transmission has been reported since its inception in 2007 [45].

\section{Products Currently Under Development}

The US Department of Defense (DoD) and the Biomedical Advanced Research and Development Authority (BARDA) are sponsoring multiple different programs to provide dried plasma products in different forms (lyophilized and spray-dried). The aim is to make the distribution, storage, and administration of plasma in combat and civilian environments safe and feasible [79].

Historically, there was a dried plasma product licensed in the USA under Plas-SD manufactured by Vitex (Melville, NY) which was required to have a black box warning due to the risk of adverse thromboembolic events caused by low levels of protein S. This was attributed to the solvent/detergent treatment. However, newer technology provided by Octaplas LG seems to have resolved the problem [79]. The Vitex product is no longer available.

HemCon Medical Technologies, Inc. (Portland, Oregon) was in the process of developing a dried plasma product for the US Army Medical Research and Materiel Command (Fort Detrick, MD) between 2008 and 2013. It was going to be a singledonor lyophilized plasma product derived from licensed FFP. In 2011, the product underwent a successful phase I clinical trial and was shown to have factors within the normal range $[17,89]$. Unfortunately, the partnership ended in 2014 due to business reasons.

Teleflex Inc. (Limerick, PA) recently acquired Vascular Solutions (Minneapolis, $\mathrm{MN}$ ) which replaced HemCon as the Army's partner in developing a single-donor, lyophilized plasma product since 2014 named RePlas. In 2017, they announced the commencement of the phase I clinical study of Ascending Doses of Autologous FDP vs FFP. This product is being developed in collaboration with the US Army Medical Materiel Development Activity (USAMMDA). They plan on having FDA approval by $2021[17,77,90,91]$.

Entegrion Inc. (Research Triangle Park, NC), in partnership with the Office of Naval Research, has been developing Resusix, a group AB, pooled, solvent/detergent spray-dried plasma under a US Navy, Marine Corps, and Defense Health 
Agency program since 2008. S/D treatment using a process licensed from Octapharma (Lachen, Switzerland) that is effective against lipid-enveloped viruses and other pathogens is utilized. The S/D process also removes immunogenic lipids, and a filtration step removes cellular debris and proinflammatory microparticles. Phase I clinical trials were completed in 2016, and developers have a goal of being licensed by 2020 [17, 92, 93]. Nova Laboratories (Leicester, UK) will perform the spray-drying and packaging for the product [79].

Velico Medical (Beverly, MA), is developing a spray-drying device and proprietary bag system (Frontline ODP) that will enable blood banks to produce licensed, single-donor, spray-dried plasma units locally within $30 \mathrm{~min}$. This program is conducted under a contract from BARDA, a part of the US Department of Health and Human Services, and is still in the preclinical phase [46, 93-95]. This product will provide a certain independence from manufacturers and allow local augmentation of production in times of need [79].

\section{Future of Lyophilized Plasma}

Damage control resuscitation is now the standard of care in the treatment of hemorrhagic shock. It is clear that trauma patients with serious injury will benefit from DCR within minutes of injury. Plasma transfusion is an integral part of this concept but suffers from several logistical constraints. This also makes it an area where significant advancements are necessary and can improve patient outcomes.

Early delivery of plasma is one avenue that seems to suffer the most. Many challenges exist that hinder this goal including physical requirements for storing and transporting FFP, required personnel, and thawing times. Certain steps taken by major trauma centers to remedy that have been successful, including having thawed plasma ready in the ED at all times and carrying thawed and liquid plasma in the prehospital setting. These measures are costly and require a large-scale operation. Smaller hospitals will not be able to accommodate such measures. Patients presenting to such facilities will suffer worse outcomes from delay in administration of plasma until it is available or until transported to a larger center. Physicians are forced to use crystalloid and colloid in such situations to stabilize patients. Furthermore, trauma casualties in remote locations requiring long transport times or austere environments requiring prolonged extrication will be at a huge disadvantage. Finally, soldiers and combat casualties are also negatively affected by the delay of plasma transfusion, which has been demonstrated over and over again.

The solution is to have a product that is readily available, easy to store and transport, and can be administered quickly and safely. Dried plasma provides all these advantages. It can be stored up to 2 years at room temperature and reconstituted within minutes. It's been shown to be safe and efficacious clinically and in animal models with similar coagulation properties to FFP.

A dried plasma product introduced in the USA will allow for earlier plasma administration starting prehospital and continuing into the hospital setting, which will likely improve patient outcomes, as demonstrated by the French experience 
[87]. Dried plasma should certainly replace the recommended crystalloid administration in the ATLS guidelines, which were designed to accommodate all levels of practice and take into account the variable availability of blood products. Taking this concept one step further, it may prove beneficial and efficient to replace FFP altogether, especially when time to transfusion is a critical element of care, thus eliminating the need for cold storage facilities and complicated thawing equipment and procedures. The future of lyophilized plasma is exciting, and while it is an old product, it will likely see a new beginning.

\section{References}

1. Holcomb J. Transport time and preoperating room hemostatic interventions are important. Crit Care Med. 2018;46(3):447-53.

2. Alarhayem A, Myers J, Dent D, Liao L, Muir M, Mueller D, et al. Time is the enemy: mortality in trauma patients with hemorrhage from torso injury occurs long before the "golden hour". Am J Surg. 2016;212(6):1101-5.

3. Holcomb J, del Junco D, Fox E, Wade C, Cohen M, Schreiber M, et al. The prospective, observational, multicenter, major trauma transfusion [PROMMTT] study. JAMA Surg. 2013;148(2): 127 .

4. Holcomb J, Jenkins D, Rhee P, Johannigman J, Mahoney P, Mehta S, et al. Damage control resuscitation: directly addressing the early coagulopathy of trauma. J Trauma. 2007;62(2):307-10.

5. Kashuk JL, Moore EE, Millikan JS, Moore JB. Major abdominal vascular trauma-a unified approach. J Trauma. 1982;22(8):672-9.

6. Bickell W, Wall M, Pepe P, Martin R, Ginger V, Allen M, et al. Immediate versus delayed fluid resuscitation for hypotensive patients with penetrating torso injuries. N Engl J Med. 1994;331(17):1105-9.

7. Holcomb J, Wade C, Michalek J, Chisholm G, Zarzabal L, Schreiber M, et al. Increased plasma and platelet to red blood cell ratios improves outcome in 466 massively transfused civilian trauma patients. Ann Surg. 2008;248(3):447-58.

8. Beecher H. Preparation of battle casualties for surgery. Ann Surg. 1945;121(6):769-92.

9. Brohi K, Singh J, Heron M, Coats T. Acute traumatic coagulopathy. J Trauma. 2003;54(6):1127-30.

10. MacLeod J, Lynn M, McKenney M, Cohn S, Murtha M. Early coagulopathy predicts mortality in trauma. J Trauma. 2003;55(1):39-44.

11. Hess J, Lindell A, Stansbury L, Dutton R, Scalea T. The prevalence of abnormal results of conventional coagulation tests on admission to a trauma center. Transfusion. 2009;49(1):34-9.

12. Maegele M, Lefering R, Yucel N, Tjardes T, Rixen D, Paffrath T, et al. Early coagulopathy in multiple injury: an analysis from the German Trauma Registry on 8724 patients. Injury. 2007;38(3):298-304.

13. Pidcoke H, Aden J, Mora A, Borgman M, Spinella P, Dubick M, et al. Ten-year analysis of transfusion in operation Iraqi freedom and operation enduring freedom. J Trauma Acute Care Surg. 2012;73:S445-52.

14. Holcomb J, Pati S. Optimal trauma resuscitation with plasma as the primary resuscitative fluid: the surgeon's perspective. Hematology. 2013;2013(1):656-9.

15. Borgman M, Spinella P, Perkins J, Grathwohl K, Repine T, Beekley A, et al. The ratio of blood products transfused affects mortality in patients receiving massive transfusions at a combat support hospital. J Trauma. 2007;63(4):805-13.

16. Pusateri A, Given M, Schreiber M, Spinella P, Pati S, Kozar R, et al. Dried plasma: state of the science and recent developments. Transfusion. 2016;56:S128-39. 
17. Spinella P, Dunne J, Beilman G, O'Connell R, Borgman M, Cap A, et al. Constant challenges and evolution of US military transfusion medicine and blood operations in combat. Transfusion. 2012;52(5):1146-53.

18. Simmons J, White C, Eastridge B, Mace J, Wade C, Blackbourne L. Impact of policy change on US Army combat transfusion practices. J Trauma. 2010;69(Supplement):S75-80.

19. Holcomb J, Tilley B, Baraniuk S, Fox E, Wade C, Podbielski J, et al. Transfusion of plasma, platelets, and red blood cells in a 1:1:1 vs a 1:1:2 ratio and mortality in patients with severe trauma: the PROPPR randomized clinical trial. JAMA. 2015;313(5):471-82.

20. Radwan Z, Bai Y, Matijevic N, del Junco D, McCarthy J, Wade C, et al. An emergency department thawed plasma protocol for severely injured patients. JAMA Surg. 2013;148(2):170.

21. Shackelford S, del Junco D, Powell-Dunford N, Mazuchowski E, Howard J, Kotwal R, et al. Association of prehospital blood product transfusion during medical evacuation of combat casualties in Afghanistan with acute and 30-day survival. JAMA. 2017;318(16):1581.

22. Holcomb J, Donathan D, Cotton B, del Junco D, Brown G, Wenckstern T, et al. Prehospital transfusion of plasma and red blood cells in trauma patients. Prehosp Emerg Care. 2014;19(1):1-9.

23. Nelson A, Statkevicius S, Schött U, Johansson P, Bentzer P. Effects of fresh frozen plasma, Ringer's acetate and albumin on plasma volume and on circulating glycocalyx components following haemorrhagic shock in rats. Intensive Care Med Exp. 2016;4(1):6.

24. Kozar R, Pati S. Syndecan-1 restitution by plasma after hemorrhagic shock. J Trauma Acute Care Surg. 2015;78:S83-6.

25. Peng Z, Pati S, Potter D, Brown R, Holcomb J, Grill R, et al. Fresh frozen plasma lessens pulmonary endothelial inflammation and hyperpermeability after hemorrhagic shock and is associated with loss of syndecan 1. Shock. 2013;40(3):195-202.

26. Kozar R, Peng Z, Zhang R, Holcomb J, Pati S, Park P, et al. Plasma restoration of endothelial glycocalyx in a rodent model of hemorrhagic shock. Anesth Analg. 2011;112(6):1289-95.

27. Halaweish I, Bambakidis T, He W, Linzel D, Chang Z, Srinivasan A, et al. Early resuscitation with fresh frozen plasma for traumatic brain injury combined with hemorrhagic shock improves neurologic recovery. J Am Coll Surg. 2015;220(5):809-19.

28. Hwabejire J, Imam A, Jin G, Liu B, Li Y, Sillesen M, et al. Differential effects of fresh frozen plasma and normal saline on secondary brain damage in a large animal model of polytrauma, hemorrhage and traumatic brain injury. J Trauma Acute Care Surg. 2013;75(6):968-75.

29. Jin G, deMoya M, Duggan M, Knightly T, Mejaddam A, Hwabejire J, et al. Traumatic brain injury and hemorrhagic shock: evaluation of different resuscitation strategies in a large animal model of combined insults. Shock. 2012;38(1):49-56.

30. Imam A, Jin G, Sillesen M, Dekker S, Bambakidis T, Hwabejire J, et al. Fresh frozen plasma resuscitation provides neuroprotection compared to normal saline in a large animal model of traumatic brain injury and polytrauma. J Neurotrauma. 2015;32(5):307-13.

31. Chang R, Folkerson L, Sloan D, Tomasek J, Kitagawa R, Choi H, et al. Early plasma transfusion is associated with improved survival after isolated traumatic brain injury in patients with multifocal intracranial hemorrhage. Surgery. 2017;161(2):538-45.

32. Hess J, Lelkens C, Holcomb J, Scalea T. Advances in military, field, and austere transfusion medicine in the last decade. Transfus Apher Sci. 2013;49(3):380-6.

33. Nessen S, Eastridge B, Cronk D, Craig R, Berséus O, Ellison R, et al. Fresh whole blood use by forward surgical teams in Afghanistan is associated with improved survival compared to component therapy without platelets. Transfusion. 2013;53:107S-13S.

34. Cotton B, Reddy N, Hatch Q, LeFebvre E, Wade C, Kozar R, et al. Damage control resuscitation is associated with a reduction in resuscitation volumes and improvement in survival in 390 damage control laparotomy patients. Ann Surg. 2011;254(4):598-605.

35. Hmel P, Kennedy A, Quiles J, Gorogias M, Seelbaugh J, Morrissette C, et al. Physical and thermal properties of blood storage bags: implications for shipping frozen components on dry ice. Transfusion. 2002;42(7):836-46.

36. Inaba K. Freeze-dried plasma. J Trauma. 2011;70:S57-8.

37. Schmidt P. The plasma wars: a history. Transfusion. 2012;52:2S-4S. 
38. Elliott J. A preliminary report of a new method of blood transfusion. South Med Surg. 1936;97:7-10.

39. Elliott J, Nesset NM. A report on the use of a perfected evacuated unit for blood transfusion. South Med Surg. 1940;102:303-5.

40. Kendrick D, Heaton L, Coates J, McFetridge E. Blood program in World War II. Washington, DC: Office of the Surgeon General, Dept. of the Army; 1989. p. 266.

41. Maroney E. A study of experimental and clinical shock with special reference to its treatment by the intravenous injection of preserved plasma. Ann Surg. 1938;108(2):178-93.

42. Watson J, Pati S, Schreiber M. Plasma transfusion: history, current realities, and novel improvements. Shock. 2016;46(5):468-79.

43. Stetten D. The blood plasma for Great Britain project. Bull N Y Acad Med. 1941;17(1):27-38.

44. Strumia MM, Wagner JA, Monaghan JF. The intravenous use of serum and plasma, fresh and preserved. Ann Surg. 1940;111:623-9.

45. Bux J, Dickhörner D, Scheel E. Quality of freeze-dried [lyophilized] quarantined single-donor plasma. Transfusion. 2013;53(12):3203-9.

46. Booth G, Lozier J, Nghiem K, Clibourn D, Klein H, Flegel W. Spray: single-donor plasma product for room temperature storage. Transfusion. 2011;52(4):828-33.

47. Stramer S, Glynn S, Kleinman S, Strong D, Caglioti S, Wright D, et al. Detection of HIV-1 and $\mathrm{HCV}$ infections among antibody-negative blood donors by nucleic acid-amplification testing. N Engl J Med. 2004;351(8):760-8.

48. Liumbruno G, Franchini M. Solvent/detergent plasma: pharmaceutical characteristics and clinical experience. J Thromb Thrombolysis. 2014;39(1):118-28.

49. Wollowitz S. Fundamentals of the psoralen-based Helinx technology for inactivation of infectious pathogens and leukocytes in platelets and plasma. Semin Hematol. 2001;38(4, Suppl 11):4-11.

50. Hambleton J, Wages D, Radu-Radulescu L, Adams M, MacKenzie M, Shafer S, et al. Pharmacokinetic study of FFP photochemically treated with amotosalen (S-59) and UV light compared to FFP in healthy volunteers anticoagulated with warfarin. Transfusion. 2002;42(10):1302-7.

51. Keil S, Bengrine A, Bowen R, Marschner S, Hovenga N, Rouse L, et al. Inactivation of viruses in platelet and plasma products using a riboflavin-and-UV-based photochemical treatment. Transfusion. 2015;55(7):1736-44.

52. Rock G. A comparison of methods of pathogen inactivation of FFP. Vox Sang. 2011;100(2):169-78.

53. McCully S, Martin D, Cook M, Gordon N, McCully B, Lee T, et al. Effect of ascorbic acid concentrations on hemodynamics and inflammation following lyophilized plasma transfusion. J Trauma Acute Care Surg. 2015;79(1):30-8.

54. Sailliol A, Martinaud C, Cap A, Civadier C, Clavier B, Deshayes A, et al. The evolving role of lyophilized plasma in remote damage control resuscitation in the French Armed Forces Health Service. Transfusion. 2013;53:65S-71S.

55. Spoerke N, Zink K, Cho SD, Differding J, Muller P, Karahan A, Sondeen J, et al. Lyophilized plasma for resuscitation in a swine model of severe injury. Arch Surg. 2009;144(9):829.

56. Lee T, Van P, Spoerke N, Hamilton G, Cho S, Watson K, et al. The use of lyophilized plasma in a severe multi-injury pig model. Transfusion. 2013;53:72S-9S.

57. Van P, Hamilton G, Kremenevskiy I, Sambasivan C, Spoerke N, Differding J, et al. Lyophilized plasma reconstituted with ascorbic acid suppresses inflammation and oxidative DNA damage. J Trauma. 2011;71(1):20-5.

58. McCully S, Lee T, McCully B, Sands C, Rick E, Dean R, et al. Reconstitution fluid type does not affect pulmonary inflammation or DNA damage following infusion of lyophilized plasma. J Trauma Acute Care Surg. 2015;78(2):231-9.

59. Lee T, McCully S, McCully B, Sands C, Hampton D, Louis S, et al. Comparison of the hemostatic efficacy of low-volume lyophilized plasma reconstituted using sterile water, lactated Ringer's, normal saline, and Hextend solutions. J Trauma Acute Care Surg. 2014;76(2): $264-72$. 
60. Matijevic N, Wang Y, Cotton B, Hartwell E, Barbeau J, Wade C, et al. Better hemostatic profiles of never-frozen liquid plasma compared with thawed fresh frozen plasma. J Trauma Acute Care Surg. 2013;74(1):84-91.

61. Matijevic N, Kostousov V, Wang Y, Wade C, Wang W, Letourneau P, et al. Multiple levels of degradation diminish hemostatic potential of thawed plasma. J Trauma. 2011;70(1):71-80.

62. Pati S, Matijevic N, Doursout M, Ko T, Cao Y, Deng X, et al. Protective effects of fresh frozen plasma on vascular endothelial permeability, coagulation, and resuscitation after hemorrhagic shock are time dependent and diminish between days 0 and 5 after thaw. J Trauma. 2010;69(Supplement):S55-63.

63. Lee T, Watson K, Fabricant L, Barton J, Differding J, Kremenevskiy I, et al. Hyperosmolar reconstituted lyophilized plasma is an effective low-volume hemostatic resuscitation fluid for trauma. J Trauma Acute Care Surg. 2013;75(3):369-75.

64. Shuja F, Finkelstein R, Fukudome E, Duggan M, Kheirbek T, Hamwi K, et al. Development and testing of low-volume hyperoncotic, hyperosmotic spray-dried plasma for the treatment of trauma-associated coagulopathy. J Trauma. 2011;70(3):664-71.

65. Heiden M, Seitz R. Quality of therapeutic plasma—requirements for marketing authorization. Thromb Res. 2002;107:S47-51.

66. Shuja F, Shults C, Duggan M, Tabbara M, Butt M, Fischer T, et al. Development and testing of freeze-dried plasma for the treatment of trauma-associated coagulopathy. J Trauma. 2008;65(5):975-85.

67. Spinella P, Frazier E, Pidcoke H, Dietzen D, Pati S, Gorkun O, et al. All plasma products are not created equal. J Trauma Acute Care Surg. 2015;78:S18-25.

68. Dombrose F, Barnes C, Gaynor J, Elston RA. Lyophilized human reference plasma for coagulation factors: evidence for stability of factors I, II, V, and VII through XII. Am J Clin Pathol. 1982;77(1):32-45.

69. Fu P, Myhre B. Chemical analysis of a 30-year-old bottle of lyophilized plasma. Transfusion. 1977;17(1):73-4.

70. Alam H, Hamwi K, Duggan M, Fikry K, Lu J, Fukudome E, et al. Hemostatic and pharmacologic resuscitation: results of a long-term survival study in a swine polytrauma model. $\mathbf{J}$ Trauma. 2011;70(3):636-45.

71. Pati S, Peng Z, Wataha K, Miyazawa B, Potter D, Kozar R. Lyophilized plasma attenuates vascular permeability, inflammation and lung injury in hemorrhagic shock. PLoS One. 2018;13(2):e0192363.

72. Wataha K, Menge T, Deng X, Shah A, Bode A, Holcomb J, et al. Spray-dried plasma and fresh frozen plasma modulate permeability and inflammation in vitro in vascular endothelial cells. Transfusion. 2013;53:80S-90S.

73. Potter D, Baimukanova G, Keating S, Deng X, Chu J, Gibb S, et al. Fresh frozen plasma and spray-dried plasma mitigate pulmonary vascular permeability and inflammation in hemorrhagic shock. J Trauma Acute Care Surg. 2015;78:S7-S17.

74. Imam A, Jin G, Sillesen M, Duggan M, Jepsen C, Hwabejire J, et al. Early treatment with lyophilized plasma protects the brain in a large animal model of combined traumatic brain injury and hemorrhagic shock. J Trauma Acute Care Surg. 2013;75(6):976-83.

75. Halaweish I, Bambakidis T, Nikolian V, Georgoff P, Bruhn P, Piascik P, et al. Early resuscitation with lyophilized plasma provides equal neuroprotection compared with fresh frozen plasma in a large animal survival model of traumatic brain injury and hemorrhagic shock. $\mathrm{J}$ Trauma Acute Care Surg. 2016;81(6):1080-7.

76. Georgoff P, Nikolian V, Halaweish I, Chtraklin K, Bruhn P, Eidy H, et al. Resuscitation with lyophilized plasma is safe and improves neurological recovery in a long-term survival model of swine subjected to traumatic brain injury, hemorrhagic shock, and polytrauma. J Neurotrauma. 2017;34(13):2167-75.

77. DoD advances development of freeze-dried plasma for battlefield deployment: U.S. medicine [Internet]. Usmedicine.com. 2018 [cited 27 March 2018]. Available from: http:// www.usmedicine.com/agencies/department-of-defense-dod/dod-advances-developmentof-freeze-dried-plasma-for-battlefield-deployment/. 
78. Gokhale S, Scorer T, Doughty H. Freedom from frozen: the first British military use of lyophilised plasma in forward resuscitation. J R Army Med Corps. 2014;162(1):63-5.

79. Pusateri A, Given M, Macdonald V, Homer M. Comprehensive US government program for dried plasma development. Transfusion. 2016;56:S16-23.

80. Sunde G, Vikenes B, Strandenes G, Flo K, Hervig T, Kristoffersen E, et al. Freeze dried plasma and fresh red blood cells for civilian prehospital hemorrhagic shock resuscitation. J Trauma Acute Care Surg. 2015;78:S26-30.

81. Gellerfors M, Linde J, Gryth D. Helicopter in-flight resuscitation with freeze-dried plasma of a patient with a high-velocity gunshot wound to the neck in Afghanistan - a case report. Prehosp Disaster Med. 2015;30(05):509-11.

82. Glassberg E, Nadler R, Gendler S, Abramovich A, Spinella P, Gerhardt R, et al. Freeze-dried plasma at the point of injury: from concept to doctrine. Shock. 2013;40(6):444-50.

83. Glassberg E, Nadler R, Rasmussen T, Abramovich A, Erlich T, Blackbourne L, et al. Pointof-injury use of reconstituted freeze-dried plasma as a resuscitative fluid: a special report for prehospital trauma care. J Trauma Acute Care Surg. 2013;75:S111-4.

84. Shlaifer A, Siman-Tov M, Radomislensky I, Peleg K, Shina A, Baruch E, et al. Prehospital administration of freeze-dried plasma, is it the solution for trauma casualties? J Trauma Acute Care Surg. 2017;83(4):675-82.

85. Daban J, Clapson P, Ausset S, Deshayes A, Sailliol A. Freeze dried plasma: a French army specialty. Crit Care. 2010;14(2):412.

86. Martinaud C, Ausset S, Deshayes A, Cauet A, Demazeau N, Sailliol A. Use of freeze-dried plasma in French intensive care unit in Afghanistan. J Trauma. 2011;71(6):1761-5.

87. Nguyen C, Bordes J, Cungi P, Esnault P, Cardinale M, Mathais Q, et al. Use of French lyophilized plasma transfusion in severe trauma patients is associated with an early plasma transfusion and early transfusion ratio improvement. J Trauma Acute Care Surg. 2018;84:780-5.

88. Garrigue D, Godier A, Glacet A, Labreuche J, Kipnis E, Paris C, et al. French lyophilized plasma versus fresh frozen plasma for the initial management of trauma-induced coagulopathy: a randomized open-label trial. J Thromb Haemost. 2018;16(3):481-9.

89. The safety of autologous lyophilized plasma versus fresh frozen plasma in healthy volunteers - full text view - ClinicalTrials.gov [Internet]. Clinicaltrials.gov. 2018 [cited 27 March 2018]. Available from: https://clinicaltrials.gov/ct2/show/NCT00968487.

90. Ascending doses of autologous FDP vs FFP - full text view - ClinicalTrials.gov [Internet]. Clinicaltrials.gov. 2018 [cited 27 March 2018]. Available from: https://clinicaltrials.gov/ct2/ show/NCT02930226.

91. Teleflex [TFX] announces commencement of Phase I clinical study [FDP-1] of RePlas ${ }^{\mathrm{TM}}$ freeze-dried plasma I Teleflex incorporated [Internet]. Teleflex incorporated. 2018 [cited 27 March 2018]. Available from: https://teleflexincorporated.gcs-web.com/news-releases/ news-release-details/teleflex-tfx-announces-commencement-phase-i-clinical-study-fdp-1.

92. Resusix ${ }^{\mathrm{TM}}$ fresh frozen plasma [FFP] hemostatic volume resuscitation therapeutic I Entegrion [Internet]. Entegrion.com. 2018 [cited 27 March 2018]. Available from: http://www.entegrion. com/products/resusix.

93. Safety study of spray-dried solvent/detergent-treated plasma for infusion in healthy volunteers - full text view - ClinicalTrials.gov [Internet]. Clinicaltrials.gov. 2018 [cited 27 March 2018]. Available from: https://clinicaltrials.gov/ct2/show/NCT01589666.

94. Velico Medical announces BARDA exercise of \$15.5 million contract option - Velico Medical [Internet]. Velicomedical.com. 2018 [cited 27 March 2018]. Available from: http://www.velicomedical.com/velico-medical-announces-barda-exercise-of-15-5-million-contract-option/.

95. Perriello B. Velico Medical raises another $\$ 19 \mathrm{~m}$ for Frontline ODP spray-dried plasma MassDevice [Internet]. MassDevice. 2018 [cited 27 March 2018]. Available from: https:// www.massdevice.com/velico-medical-raises-another-19m-frontline-odp-spray-dried-plasma/. 